\title{
REVIEW
}

\section{Evidence based prevention of hamstring injuries in sport}

\author{
J Petersen, P Hölmich
}

Br J Sports Med 2005;39:319-323. doi: 10.1136/bjsm.2005.018549

A common soft tissue injury in sports involving sprinting and jumping is the hamstring strain. A major problem with hamstring strains is the high incidence of reinjury. Muscle injuries can be classified as direct or indirect and are typically grouped into three categories according to severity. A number of potential risk factors have been proposed for hamstring strains. Only a few are evidence based and some are mainly based on theoretical assumptions. There is a lack of clinical research on the effectiveness of rehabilitation programmes for hamstring strains. Although the initial treatment of rest, ice, compression, and elevation is accepted for muscle strains, no consensus exists for their rehabilitation. Not much evidence based research has been carried out on prevention of hamstring strain. To our knowledge only two prospective studies have so far been published. As the injuries are common in football and other sports involving sprinting and jumping, there is a need for further research preferably in the form of randomised controlled trials.

See end of article for authors' affiliations

.....................

Correspondence to: Associate

Professor Holmich, Department of Orthopaedic Surgery, Amager University Hospital, Copenhagen DK2300 S, Denmark; per.holmich@ah.hosp.dk

Accepted 15 March 2005
$\mathrm{T}$ his review is based on computerised searches using Medline (from 1966 to 2005) and Embase (from 1988 to 2005). The following search terms were used individually or in various combinations: hamstring, muscle, strain, injury, prevention. Only English language publications were considered. Other references were identified from existing reviews or other papers cited in the publications searched. Unpublished reports and abstracts were not considered. This is not a systematic review.

\section{INTRODUCTION}

Hamstring muscle strain is a frustrating injury, athletes. It is frustrating because the symptoms are persistent, healing is slow, and the rate of reinjury is high.

Hamstring strains are among the most common injuries in sports that involve sprinting and jumping,,$^{2}$ but are also common in dancing and waterskiing. ${ }^{3}$ Most epidemiological studies of hamstring strains have focused on injury prevalence in football including Australian football. ${ }^{15-8}$ Several studies have been carried out on hamstring injuries in Australian Rules football. ${ }^{--}$ ${ }^{10}$ It has been shown that hamstring strain injuries account for $12-16 \%$ of all injuries in English and Australian professional football. A rate of five to six hamstring strain injuries per club per season has been observed, resulting in well known to medical staff, coaches, and
90 days $^{6}$ and 15-21 matches missed per club per season on average. ${ }^{6}$ This results in, on average, 18 days and 3-3.5 matches missed per hamstring strain, but the individual variation in absence from sports participation is not described. The variation may differ from one or a few days to several months.

The reinjury rate for hamstring injuries has been found to be $12-31 \% .^{611} 12$

A brief review of classification, mechanism of injury, aetiological factors, and the current trends in treatment is included before discussion of evidence based prevention of hamstring injuries.

To our knowledge, there is only one prospective, randomised study of treatment in the literature and two prospective studies on prevention of hamstring strain injuries. It is difficult to compare the studies with respect to risk factors because of different methodology.

\section{INJURY DEFINITION}

Injuries are most often defined as an incident occurring during scheduled games/competitions or practice and causing the athlete to miss the next game/competition or practice session.

\section{CLASSIFICATION}

Depending on the trauma mechanism, muscle injuries can be classified as direct and indirect. The direct forms are laceration and contusion, and the indirect form is strain. Indirect injuries can be either complete or incomplete. Hamstring muscle injuries are usually strains, but contusions occur in contact sports. ${ }^{13} 14$

Complete rupture usually occurs as an avulsion injury from the ischial tuberosity. Avulsion injuries can be entirely soft tissue or involve a bony fragment or the ischial apophysis. ${ }^{14}{ }^{15}$ This injury is commonly documented among water skiers. ${ }^{4}$

Strains usually occur in the biceps femoris, ${ }^{2}{ }^{6}$ and the most common location is near the muscle-tendon junction. ${ }^{2}{ }^{16}$

Muscles injuries represent a continuum from mild muscle cramp to complete muscle rupture, and in between is delayed onset muscle soreness and partial strain injury. Muscle strains can be divided into three grades according to their severity: ${ }^{114}$

- mild (first degree) strain/contusion: tear of a few muscle fibres with minor swelling and discomfort and with no, or only minimal, loss of strength and restriction of movements

- moderate (second degree) strain/contusion: greater damage of muscle with a clear loss of strength 
- severe (third degree) strain/contusion: a tear extending across the whole cross section of the muscle resulting in a total lack of muscle function

In practice the diagnosis is based on an accurate history and a physical examination. In typical cases, no need for further examination is needed. In the study by Woods et al, ${ }^{6}$ imaging techniques were used in only $5 \%$ of the cases. If there is any doubt, magnetic resonance imaging (MRI) or sonography can be useful. Connell et $a l^{10}$ concluded that sonography is as useful as MRI in depicting acute hamstring injuries and, because of lower costs, may be the preferred imaging technique.

\section{MECHANISM OF INJURY}

In order to prevent hamstring injuries, it is important to establish how they happen. It is commonly thought that one reason for the susceptibility of hamstring muscles to injury is their anatomical arrangement. The hamstring muscle complex is a biarticular muscle group which works by flexing the knee and extending the hip. In everyday movements, flexion of the hip and knee occur together, with opposing effects on hamstring length.

In football, most hamstring strains occur while players are running or sprinting. ${ }^{67}$ Most studies suggest that hamstring strains occur during the later part of the swing phase when the hamstrings are working to decelerate knee extensionthat is, the muscle develops tension while lengthening. This means that the hamstrings must change from functioning eccentrically, to decelerate knee extension in the late swing, to concentrically, becoming an active extensor of the hip joint. ${ }^{6}{ }^{13} 15$ It has been suggested that it is during this rapid change from eccentric to concentric function that the muscle is most vulnerable to injury. ${ }^{9}$

Hamstring injuries to elite water skiers are typically severe and involve the proximal hamstring muscles. In the study by Sallay et al, ${ }^{4}$ the expert skiers sustained injury secondary to a fall while skiing.

Hamstring strain injuries in elite dancing has been little studied, although they are common among students of classical ballet and modern dance at the Ballet Academy in Stockholm, Sweden. ${ }^{3}$ In the study by Askling et al, ${ }^{17}$ which describes the injury mechanism in one female professional dancer, the injury occurred during slow stretching. It was localised to the proximal tendon of the semimembranosus muscle. The type of dancing was not reported.

\section{AETIOLOGICAL FACTORS}

Understanding the individual risk factors for injury is important as a basis for developing preventive measures. Risk factors are traditionally divided into two main categories: internal (intrinsic) and external (extrinsic). However, it would be more relevant to make a distinction between modifiable and non-modifiable. ${ }^{18}$ A number of potential risk factors have been proposed for hamstring strains. Only a few are evidence based, and some are mainly based on theoretical assumptions. The most common non-modifiable factors in the literature are older age $^{6919}$ and black or aboriginal ethnic origin. ${ }^{69}$

The most common modifiable factors are imbalance of muscular strength with a low hamstring to quadriceps ratio (H:Q ratio), ${ }^{13-15} 20-24$ muscle fatigue, ${ }^{6} 141521222425$ hamstring tightness, ${ }^{2} 1415202122242627$ insufficient warm up, ${ }^{14} 15202224$ and previous injury. ${ }^{2} 913151920$

In the theoretical model proposed by Worrell, ${ }^{22}$ he suggest that a combination of abnormalities (strength, flexibility, warm up, fatigue) increases the risk of hamstring strain. As suggested by Devlin, ${ }^{28}$ there may be a threshold at which the number of risk factors produces an injury, or some factors may be more predictive of injury than others.
Athletes who return to sport before full recovery are at risk of recurrent and possibly more severe injury. ${ }^{15}$

It remains unclear if decreased hamstring flexibility is a cause or consequence of hamstring injury because most information about risk factors are collected retrospectively. ${ }^{18}$ A recent prospective cohort study by Witvrouw et $a l^{27}$ indicates that soccer players with increased tightness of the hamstring muscles have a significantly higher risk of a subsequent musculoskeletal lesion. In the study, 146 male professional soccer players were examined before the 1999/ 2000 Belgian soccer season. None of the players had a history of muscle injury in the lower extremities in the previous two years. The study showed that players who sustained a hamstring muscle injury in the season 1999/2000 had significantly less flexibility in the hamstring muscles before their injury compared with the uninjured group.

\section{TREATMENT}

There is a lack of clinical research on the effectiveness of rehabilitation programmes for hamstring strains. Although the initial treatment of rest, ice, compression, and elevation is accepted for muscle strains, no consensus exists for their rehabilitation.

Most rehabilitation programmes are based on the tissue's theoretical healing response. To our knowledge, there is only one prospective, randomised controlled study in the literature that investigated the effectiveness of different rehabilitation programmes for the treatment of acute hamstring strains. This is the study by Sherry and Best ${ }^{11}$ in which two different rehabilitation programmes were compared. Eleven athletes were assigned to a protocol consisting of static stretching, isolated progressive hamstring resistance, and icing (STST group). Thirteen athletes were assigned to a programme of progressive agility and trunk stabilisation exercises and icing (PATS group). No significant difference was found between the groups with regard to time required to return to sport, but there was a significant difference with regard to the reinjury rate after two weeks and one year. After two weeks, six of 11 athletes in the STST group had suffered a recurrent hamstring strain compared with none of the athletes in the PATS group. After one year, seven of 10 athletes in the STST group compared with one of 13 athletes in the PATS group had suffered a recurrent hamstring strain.

In general, the primary objective of rehabilitation programmes is the restoration of function to the greatest possible degree in the shortest possible time. Treatment is traditionally classified into different phases according to the length of time since the injury occurred. The following classification is based on the treatment protocol of Clanton et al, ${ }^{13}$ but does not differ essentially from other classifications. There is an overlap in the time in the different phases because of the difference in injury severity.

\section{Phase I (acute): 1-7 days}

The most used treatment in muscle strains, including hamstring strains, in the acute phase is the rest, ice, compression, and elevation regimen. The goal of this treatment is to control haemorrhaging and minimise inflammation and pain. ${ }^{13} 1522$

Non-steroidal anti-inflammatory drugs are an almost universally accepted treatment, and the only controversial aspect to their use is the appropriate timing of administration. ${ }^{13}$ The most common recommendation in the literature is short term use (3-7 days) starting immediately after the injury. ${ }^{13-15}$ However, theoretically it would be beneficial to delay the treatment until 2-4 days after the injury, because they interfere with chemotaxis of cells which is necessary for the repair and remodelling of regenerating muscle. ${ }^{13}$ 
Early motion exercise is theoretically important to prevent or decrease adhesion within the connective tissue. ${ }^{22}$ Active knee flexion and extension exercises could be performed during the treatment with ice. It is important that the exercises are pain free to prevent further injury during the rehabilitation.

\section{Phase II (subacute): day 3 to $>3$ weeks}

This phase begins when the signs of inflammation (swelling, heat, redness, and pain) begin to resolve. In this phase it is important to continue muscle action to prevent atrophy and promote healing. Regular concentric strength exercises can begin in this phase when the athlete has achieved full range of motion without pain. ${ }^{15}$ The common recommendation in this stage is multiple joint angle, submaximal isometric contraction. ${ }^{13} 1522$ If the athlete experiences pain, the intensity should be decreased.

In this phase other activities can be initiated to maintain cardiovascular fitness. This could be stationary bike riding, swimming, or other controlled resistance activities.

\section{Phase III (remodelling); 1-6 weeks}

Loss of flexibility is a characteristic feature of hamstring strains. ${ }^{13} 1522$ This is probably due to pain, inflammation, and connective tissue scar formation. ${ }^{13} 29$ To avoid the hamstring muscle becoming less flexible after the injury, hamstring stretching can begin in the third phase. In the study by Malliaropoulos et al, ${ }^{30}$ the stretching component in rehabilitation of acute hamstring strains in 80 athletes was started after 48 hours. The study compared two different rehabilitation programmes. The only difference was the number of stretching sessions. Each session consisted of a static stretch of the hamstring muscles, sustained for 30 seconds, repeated four times. One group had one session daily whereas the other group had four sessions. The athletes were advised to stretch until they felt tension or slight pulling, but no pain. The study showed that the group who performed the more intensive stretching programme regained range of motion faster and had a shorter rehabilitation period. Both these differences were significant.

Eccentric strengthening can also begin in the third phase. Concentric exercise is begun before eccentric exercise because eccentric contraction causes greater force than concentric contraction. ${ }^{9}$ It is therefore important that the eccentric exercises are delayed until the injured muscle is well regenerated to avoid a rehabilitation induced reinjury.

\section{Phase IV (functional): 2 weeks to 6 months}

The goal in this phase is return to sport without reinjury. This is achieved by increasing hamstring strength and flexibility to the normal values for the individual athlete. Simultaneously pain-free running activities are increased from jogging at low intensity to running and finally sprinting. Pain-free participation in sports specific activities is the best indicator of readiness to return to play. ${ }^{22}$ Return to competition before this time may result in recurrent or more severe injury. ${ }^{15}$

Phase V (return to competition): 3 weeks to 6 months When the athlete has returned to competition, the goal is to avoid reinjury. The focus should therefore be on maintaining stretching and strengthening. ${ }^{22}$

\section{Surgery}

Operative treatment is rarely considered for the treatment of muscle strains, including hamstring strains. Extensive bleeds are occasionally evacuated by puncture or surgery because large intramuscular haematomas can adversely influence scar formation and lead to ossification. ${ }^{24}$ With complete rupture of the proximal or distal attachment of the musculotendinous complex into bone, surgery is a realistic consideration. This is seldom the case in football but is a common problem in water skiing injuries. ${ }^{13}$

As shown by Speer et al, ${ }^{31}$ follow up computed tomography or MRI after an acute muscle strain injury reveals atrophy, fibrosis, and calcium deposition. We found no evidence in the literature on any possible indication for, or benefit of, surgery in these cases.

\section{PREVENTION}

Woods et $a l^{6}$ performed an epidemiological study of hamstring injuries. The medical staff in 91 professional football clubs annotated player injuries over two seasons. A specific injury audit questionnaire was used together with a weekly form that documented each club's current injury status. The study found that some football clubs sustained very few hamstring strains throughout the two seasons, whereas other clubs reported a high rate of recurrence. This may represent a large number of variables in diagnosis, training techniques, and medical management, but it does at least suggest that these injuries can be prevented and managed. ${ }^{\circ}$

Not much evidence based research has been carried out on prevention of hamstring strain. To our knowledge, only two prospective studies have so far been published: one investigated flexibility and hamstring strains ${ }^{26}$ and the other strength training with eccentric overload. ${ }^{32}$ In addition, some animal experimental studies have researched the preventive effect of stretching and warm up and the importance of fatigue in strain injuries. ${ }^{16} 2533$

\section{Flexibility}

The study by Hartig et al ${ }^{26}$ prospectively followed two groups of military infantry basic trainees both carrying out a scheduled fitness programme over 13 weeks. One group followed the regular fitness programme, and the other group added three hamstring stretching sessions (before lunch, dinner, and bedtime) on each day of the 13 weeks. Stretching was performed standing while another person held the leg with the hip in a $90^{\circ}$ flexed position. The subject then moved his trunk forward with an anterior tilt at the pelvis, keeping the back straight and the head in a neutral position, until he perceived a hamstring muscle stretching sensation without pain. Each stretch was performed five times for each extremity and was held for 30 seconds. The study showed that flexibility increased significantly in the intervention group compared with the control group. The number of injuries was also significantly lower in the intervention group (incidence rate $16.7 \% \vee 29.1 \%$ ).

Magnusson et $a l^{34}$ examined the effect of repeated static stretches. Five consecutive stretches for 90 seconds were performed with a 30 second rest between stretches. One last stretch was performed after one hour. It was concluded that the effect of five repeated stretches was significant one hour later. $^{34}$ Also an animal in vitro study performed by Taylor et $a l^{33}$ found sustained muscle-tendon unit elongation after cyclic and static stretching of rabbit extensor digitorum longus and tibialis anterior muscle-tendon units. Furthermore it was found that there was little alteration in the muscle after four stretches, implying that a minimum number of stretches will lead to most of the elongation in repetitive stretching.

The study by Witvrouw et $a^{27}$ indicates that it is possible by flexibility testing to identify male soccer players at risk of developing hamstring muscle injuries. Thereby it may be possible to prevent some of these injuries in elite soccer. Whether increased flexibility is an advantage or disadvantage in prevention of hamstring strain in other sports is not known. Further prospective studies are needed to investigate this issue. 
What is already known on this topic

Hamstring injuries, usually in the form of a strain, are very common and can be long standing and prone to recurrence.

\section{Strength}

The study by Askling et al ${ }^{32}$ examined the effect of preseason strength training with eccentric overload in Swedish elite soccer players. Thirty players were randomly divided into two groups: a training group and a control group. The only difference between the groups was that the training group received additional specific hamstring training during a 10 week preseason period. The training group performed a total of 16 sessions of specific hamstring strength training, every fifth day for the first four weeks and every fourth day during the last six weeks. The specific hamstring training consisted of both concentric and eccentric actions and was performed on an ergometer. The study showed a significant increase in both concentric and eccentric strength in the training group compared with the control group. Furthermore, maximum running speed was increased in the training group compared with the control group. The most important result of the study was that the number of hamstring injuries decreased significantly in the training group. Of the $13(13 / 30)$ reported hamstring injuries in the two groups during the 10 month study period, $10(10 / 15)$ occurred in the control group and only three (3/15) in the training group. The decrease in injury prevalence in the training group was significant, but the low number of subjects is a limitation to this study.

In the study by Mjølsnes et al, ${ }^{35}$ two hamstring strength training programmes were compared. One programme included traditional hamstring curls (concentric training) whereas the other (Nordic hamstrings) was a partner exercise focusing on the eccentric phase. The study showed that it is possible to significantly increase the eccentric torque in well trained soccer players during a 10 week training programme focusing on eccentric strength training. No significant change in strength was seen in the group focusing on concentric training. ${ }^{35}$ The study did not include any follow up on hamstring strain injuries that occurred after the hamstring strength training programmes.

We therefore recommend that a randomised controlled trial study should be carried out with enough players included to examine the potential association between strength (concentric and eccentric) and hamstring muscle strain injuries.

\section{Warm up}

The benefits of warming up in reducing the incidence of injury have been studied by Safran et al. ${ }^{16}$ They performed an in vitro animal study focusing on force, change of length required to tear the muscle, site of failure, and length-tension deformation in isometrically preconditioned (stimulated) versus control (non-stimulated) rabbit muscle. The tested muscles were stimulated before stretching and compared with their contralateral non-stimulated controls. The rabbit muscles used were the tibialis anterior, the extensor digitorum longus, and the flexor digitorum longus. The study showed that: $(a)$ the preconditioned muscles required more force to fail than the contralateral controls; $(b)$ preconditioned muscle can be stretched to a greater length from rest before failing than the non-preconditioned controls; (c) the site of failure was not altered by condition-in all muscles the site of failure was the musculotendinous junction; $(d)$ the preconditioned muscle attained less force at each given increase in length before failure.
What this study adds

This review reveals that existing knowledge on aetiology, diagnosis, treatment, and prevention of hamstring injuries is not often evidence based. Further research with well designed prospective studies and randomised controlled trials is needed.

This study therefore indicates that isometric warm up before exercise has the potential to prevent muscle strain injury.

\section{Fatigue}

In the epidemiological study of injuries sustained in English professional football by Woods et $a l^{6}{ }^{6}$ it was reported that hamstring injuries that occurred during competition represented $62 \%$ of all reported hamstring injuries. Significantly more of the injuries during competition occurred towards the end of both halves. This may indicate that fatigue is involved.

The in vitro animal study by Mair et $a l^{25}$ investigated the role of fatigue in muscle strain injuries. Extensor digitorum longus muscles from rabbits were fatigued to different degrees, then stretched to failure and compared with their non-fatigued contralateral controls. The data showed that muscles are injured at the same length, regardless of the effects of fatigue. However, fatigued muscles are able to absorb less energy before reaching the degree of stretch that causes injuries.

Most human studies on hamstring strain prevention have involved male soccer players. Whether the results can be used in the prevention of hamstring muscle injuries in other sports are not known. Further studies are required.

\section{PERSPECTIVES}

Not much evidence based research has been published on the prevention and treatment of hamstring strain injury. As the injuries are common in football and other sports involving sprinting and jumping, there is a need for further research, preferably in the form of randomised controlled trials.

The correct timing for return to sport after a hamstring injury is traditionally based on normalised strength and flexibility and the ability to carry out sport specific activities without pain. However, the healing process after a hamstring strain may be much slower than the clinical findings would indicate, and there is a need for further studies on this.

Future studies on prevention of hamstring injuries should, in our opinion, be based on the modifiable risk factors found in epidemiological research studies: muscular strength imbalance with a low hamstring-quadriceps ratio, muscle fatigue, hamstring tightness, insufficient warm up, and previous injury.

To detect further risk factors for hamstring strain injury, it is important that sample size is carefully considered, as discussed by Bahr and Holme. ${ }^{18}$

Fortunately the factors flexibility, strength, and endurance are also essential for maximum performance. It is therefore expected that athletes and trainers will be even highly motivated to focus on these topics.

\section{Authors' affiliations}

J Petersen, P Hölmich, Department of Orthopaedic Surgery, Amager University Hospital, Copenhagen Denmark

Competing interests: none declared 


\section{REFERENCES}

1 Ekstrand J, Gillquist J. Soccer injuries and their mechanisms: a prospective study. Med Sci Sports Exerc 1983;15:267-70.

2 Garrett WE Jr. Muscle strain injuries. Am J Sports Med 1996;24(6 suppl):S2-8.

3 Askling $\mathrm{C}$, Lund $\mathrm{H}$, Saartok T, et al. Self-reported hamstring injuries in student dancers. Scand J Med Sci Sports 2002;12:230-5.

4 Sallay PI, Friedman RL, Coogan PG, et al. Hamstring muscle injuries among water skiers. Functional outcome and prevention. Am J Sports Med 1996;24:130-6.

5 Hawkins RD, Hulse MA, Wilkinson C, et al. The association football medical research programme: an audit of injuries in professional football. Br J Sports Med 2001;35:43-7.

6 Woods C, Hawkins RD, Maltby S, et al. The football association medical research programme: an audit of injuries in professional football: analysis of hamstring injuries. Br J Sports Med 2004;38:36-41.

7 Arnason A, Gudmundsson A, Dahl HA, et al. Soccer injuries in Iceland. Scand J Med Sci Sports 1996;6:40-5

8 Orchard J, Seward H. Epidemiology of injuries in the Australian Football League, season 1997-2000. Br J Sports Med 2002;36:39-44.

9 Verrall GM, Slavotinek JP, Barnes PG, et al. Clinical risk factors for hamstring muscle strain injury: a prospective study with correlation of injury by magnetic resonance imaging. Br J Sports Med 2001;35:435-9.

10 Connell Da, Schneider-Kolsky ME, Hoving JL, et al. Longitudinal study comparing sonographic and MRI assessments of acute and healing hamstring injuries. AJR Am J Roentgenol 2004;183:975-84.

11 Sherry MA, Best TM. A comparison of 2 rehabilitation programs in the treatment of acute hamstring strains. J Orthop Sports Phys Ther 2004;34:116-25.

12 Heiser TM, Weber J, Sullivan G, et al. Prophylaxis and management of hamstring muscle injuries intercollegiate football players. Am J Sports Med 1984; 12:368-70

13 Clanton TO, Coupe KJ. Hamstring strains in athletes: diagnosis and treatment J Am Acad Orthop Surg 1998;6:237-48.

14 Kujala UM, Orava S, Järvinen M. Hamstring injuries: current trends in treatment and prevention. Sports Med 1997;23:397-404.

15 Drezner JA. Practical management: hamstring muscle injuries. Clin J Sport Med 2003;13:48-52.

16 Safran MR, Garrett WE, seaber AV, et al. The role of warm up in muscular injury prevention. Am J Sports Med 1988;16:123-9.

17 Askling C, Tengvar M, Saartok T, et al. Sports related hamstring strains: two cases with different etiologies and injury sites. Scand J Med Sci Sports $2000 ; 10: 304-7$.
18 Bahr R, Holme I. Risk factors for sports injuries: a methodological approach. Br J Sports Med 2003;37:384-92.

19 Arnason A, Sigurdsson SB, Gudmundson A, et al. Risk factors for injuries in football. Am J Sports Med 2004;32(1 suppl):S5-16.

20 Agre JC. Hamstring injuries. Proposed aetiological factors, prevention, and treatment. Sports Med 1985;2:21-33.

21 Coole WG, Gieck JH. An analysis of hamstring strains and their rehabilitation. J Orthop Sports Phys Ther 1987;9:77-85.

22 Worrell TW. Factors associated with hamstring injuries: an approach to treatment and preventative measures. Sports Med 1994;17:338-45.

23 Croisier J-L, Forthomme B, Namurois $\mathrm{M}-\mathrm{H}$, et al. Hamstring muscle strain recurrence and strength performance disorders. Am J Sports Med 2002;30:199-203.

24 Croisier J-L. Factors associated with recurrent hamstring injuries. Sports Med 2004; 34:681-95.

25 Mair SD, Seaber AV, Glisson RR, et al. The role of fatigue in susceptibility to acute muscle strain injury. Am J Sports Med 1996;24:137-43.

26 Hartig DE, Henderson JM. Increasing hamstring flexibility decreases lower extremity overuse in military basic trainees. Am J Sports Med 1999;27:173-6.

27 Witurouw E, Danneels L, Asselman P, et al. Muscle flexibility as a risk factor for developing muscle injuries in male professional soccer players. A prospective study. Am J Sports Med 2003;31:41-6.

28 Devlin L. Recurrent posterior thigh symptoms detrimental to performance in rugby union: predisposing factors. Sports Med 2000;29:273-87.

29 Garrett WE Jr, Rich FR, Nikolaou PK, et al. Computer tomography of hamstring muscle strains. Med Sci Sports Exerc 1989;21:506-14.

30 Malliaropoulos N, Papalexandris S, Papalada A, et al. The role of stretching in rehabilitation of hamstring injuries: 80 athletes follow-up. Med Sci Sports Exerc 2004;36:756-9.

31 Speer KP, Lohnes J, Garrett WE Jr. Radiographic imaging of muscle strain injury. Am J Sports Med 1993;21:89-96.

32 Askling C, Karlsson J, Thorstensson A. Hamstring injury occurrence in elite soccer players after preseason strength training with eccentric overload. Scand J Med Sci Sports 2003;13:244-50.

33 Taylor DC, Dalton JD Jr, Seaber AV, et al. Viscoelastic properties of muscletendon units. The biomechanical effects of stretching. Am J Sports Med 1990;18:300-9.

34 Magnusson SP, Simonsen EB, Aagaard P, et al. Viscoelastic response to repeated static stretching in the human hamstring muscle. Scand J Med Sci Sports 1995;5:342-7.

35 Miølsnes R, Arnason A, Østhagen T, et al. A 10-week randomized trial comparing eccentric vs. concentric hamstring strength training in well-trained soccer players. Scand J Med Sci Sports 2004;14:311-17. 